\title{
Influence of the Antarctic Circumpolar Wave upon New Zealand Temperature and Precipitation during Autumn-Winter
}

\author{
WARREN B. WHITE \\ Scripps Institution of Oceanography, University of California, San Diego, La Jolla, California \\ NEIL J. CHERRY \\ Lincoln University, Canterbury, New Zealand
}

(Manuscript received 8 October 1997, in final form 30 April 1998)

\begin{abstract}
Autumn-winter temperature and precipitation records at 34 stations over New Zealand from 1982 to 1995 are found by empirical orthogonal function (EOF) analysis to fluctuate together with 3-6-yr quasi periodicity similar to that associated with the Antarctic Circumpolar Wave (ACW), which propagates slowly eastward past New Zealand in its global traverse around the Southern Ocean. By allowing these EOF time sequences to represent New Zealand temperature and precipitation indices, both the positive temperature index related to warm sea surface temperature (SST) anomalies around New Zealand and the positive precipitation index related to warm (cool) SST anomalies north and east (south and west) of New Zealand are found. These warm (cool) SST anomalies are associated with poleward (equatorward) meridional surface wind (MSW) anomalies, the same as observed in association with the ACW. When warm (cool) SST and poleward (equatorward) MSW anomalies are located north (south) of New Zealand, then anomalous low-level wind convergence occurs over New Zealand, and when they are located east (west) of New Zealand, then anomalous cyclonicity occurs over New Zealand, both during years of anomalously high autumn-winter precipitation over New Zealand. Regular eastward propagation of the ACW past New Zealand suggests that covarying SST and MSW anomalies (and New Zealand autumn-winter temperature and precipitation) can be predicted 1-2 yr into the future. The authors test for this by utilizing the eastward propagation of the ACW contained in the dominant extended EOF mode of SST anomalies upstream from New Zealand to predict SST indices in the western South Pacific that are linked statistically to New Zealand temperature and precipitation indices. At 0 -yr lead, this statistical climate prediction system nowcasts the observed sign of New Zealand temperature (precipitation) indices 12 (12) years out of the 14-yr record, explaining 50\% (62\%) of the interannual variance for each index. At 1-yr lead, it hindcasts the observed sign of New Zealand temperature (precipitation) indices 12 (13) years out the 14-yr record, explaining $24 \%(74 \%)$ of the interannual variance. At 2 -yr lead, hindcasting is insignificant. This hindcast skill at 1-yr lead suggests that prediction of interannual climate variability over New Zealand may depend more upon predicting the amplitude and phase of the ACW than upon predicting it for tropical ENSO.
\end{abstract}

\section{Introduction}

In earlier studies, New Zealand temperature, precipitation, and stream flow anomalies have been compared with regional sea surface temperature (SST) and meridional surface wind (MSW) anomalies (Kidson and Gordon 1986; Moss et al. 1994; Basher and Thompson 1996). On interannual timescales, Basher and Thompson (1996) found New Zealand temperature anomalies correlated with local SST and MSW anomalies, with warm (cool) temperature anomalies associated with poleward (equatorward) MSW anomalies. Their interpretation of

Corresponding author address: Dr. Warren B. White, Physical Oceanography Research Division, Scripps Institution of Oceanography, 9500 Gilman Drive, La Jolla, CA 92093-0230.

E-mail: wbwhite@ucsd.edu these associations has New Zealand temperature and regional SST anomalies together responding to sensible plus latent heating induced by anomalous meridional heat advection in the lower troposphere by the MSW anomalies. They linked the latter to the Southern Oscillation index (SOI) via meridional atmospheric teleconnections, finding cool (warm) New Zealand temperatures during El Niño (La Niña). Kidson and Gordon (1986) found that New Zealand precipitation anomalies also correlated with local atmospheric circulation anomalies, with positive precipitation anomalies occurring during periods of anomalous cyclonicity over New Zealand, the latter indicative of greater synoptic storm activity during winter-spring. But they found little consistent relationship between New Zealand precipitation and the SOI, as with New Zealand stream flow anomalies (Moss et al. 1994).

Recently, covarying SST and MSW anomalies in the 
vicinity of New Zealand have also been linked to a climate change phenomenon of the Southern Ocean called the Antarctic Circumpolar Wave (ACW). The ACW is a nominal 4-yr climate signal in the oceanatmosphere system, propagating eastward at an average speed of $45^{\circ}$ of longitude per year, taking approximately 8 yr to circle the Southern Ocean with global zonal wavenumber 2 (White and Peterson 1996). The ACW is characterized by a persistent phase relationship between warm (cool) SST anomalies and poleward (equatorward) MSW anomalies. This relationship is consistent with that observed by Basher and Thompson (1996) in the vicinity of New Zealand. But, because SST anomalies are advected eastward by the broad-scale flow of the Antarctic Circumpolar Current (ACC) over at least part of the Southern Ocean (i.e., the eastern Pacific, the Atlantic, and western Indian Ocean sectors), this suggested to White and Peterson (1996) that these MSW anomalies are in thermodynamical equilibrium with underlying SST anomalies. This is a different interpretation from that reached by Basher and Thompson (1996), where the MSW anomalies were presumed to derive from meridional atmospheric teleconnections driven by equatorial SST anomalies associated with tropical ENSO.

Whether equatorward MSW anomalies warm the underlying SST anomalies or are in dynamical equilibrium with them seems to be a matter of scale. Analyses of anomalous upper-ocean heat budgets in the extratropical North Pacific find SST anomalies driven by fluctuating sensible-plus-latent heat fluxes on synoptic and monthly timescales but driving them on longer timescales (Haney 1986). For example, Kraus and Morrison (1966) found air-sea temperature differences in extratropical North Pacific and North Atlantic Oceans dominated by air temperature on timescales shorter than a month but by sea temperatures on timescales longer than a month. Frankignoul and Reynolds (1983) found that they could only simulate the observed frequency spectrum of SST anomalies in the interior North Pacific Ocean (driven by white noise heating by the atmosphere) by assuming damping timescales of several months stemming from anomalous heat loss to the atmosphere driven by SST anomalies. Namias (e.g., 1972, 1985) argued for many years that this anomalous SST-driven heat loss to the atmosphere on seasonal-to-interannual timescales has a significant influence upon the intensity and/or track of aggregate synoptic storm activity occurring during autumn-winter, manifested in seasonal-to-interannual sea level pressure (SLP) anomaly patterns in the extratropics. Later, Wallace and Jiang (1987) emphasized that even on seasonal timescales both influences could occur, but with different temporal phasing; that is, autumnwinter SLP anomalies associated with the Pacific-North America pattern occur contemporaneously and in thermodynamical equilibrium with underlying SST anomalies, while the anomalous time rate of change in SST is driven by anomalous wind-driven processes associated with the overlying SLP anomalies.

To understand the thermodynamic equilibrium accounting for covarying extratropical SST and MSW anomaly patterns during autumn-winter, Palmer and Sun (1985) addressed the scale analyses performed on anomalous potential temperature and potential vorticity budgets by Hoskins and Karoly (1981). To conserve potential temperature, Hoskins and Karoly (1981) had proposed that positive diabatic heating anomalies near the sea surface (i.e., presumably induced by warm SST anomalies) in the extratropics are balanced principally by anomalous equatorward heat advection, as had been proposed even earlier by Smagorinsky (1953) for the autumn-winter mean state; to conserve potential vorticity, they argued that the resulting equatorward lowlevel wind anomalies are principally balanced by anomalous low-level divergence and anomalous midlevel descent. To the contrary, Palmer and Sun (1985) found poleward low-level wind anomalies in the extratropical North Atlantic basin overlying warm SST anomalies, as did Namias (1985) and Wallace and Jiang (1987) in the North Pacific Ocean, and went on to simulate these observations in the atmospheric general circulation model experiments. They argued that SST anomalies induce midlevel diabatic heating (not low-level diabatic heating as presumed by Hoskins and Karoly 1981), which is balanced principally by anomalous vertical heat advection, yielding vertical ascent over warm SST anomalies; to conserve potential vorticity, they argued that the corresponding low-level convergence is balanced principally by anomalous planetary vorticity advection by poleward low-level wind anomalies.

In subsequent couple modeling of the ACW, White et al. (1998) demonstrated how this anomalous poleward MSW equilibrium response to warm SST anomalies proposed by Palmer and Sun (1985) can produce a positive feedback to the ocean that maintains the ACW against dissipation as it propagates slowly around the Southern Ocean. To achieve this, White et al. (1998) developed a climate model for the lower troposphere following the dynamical prescription given by Palmer and Sun (1985), coupling it to a prognostic heat budget model for the upper ocean, the latter governing the anomalous wind-driven time rate-of-change in SST, consistent with Wallace and Jiang (1987). When coupling in this model is turned off, the broad-scale flow of the ACC from $30^{\circ}$ to $70^{\circ} \mathrm{S}$ advects SST anomalies from initial conditions to the east at speeds slower than observed, taking 12-14 yr to circle the globe with amplitudes that become insignificant after 6-8 yr. But when coupling in the model is turned on, eastward speeds of the ACC are matched by those due to coupling, together yielding a model ACW of nominal 4-yr period that circles the globe in approximately $8 \mathrm{yr}$ at global zonal wavenumber 2 , as observed. Both the maintenance and the coupling speed of the model ACW were achieved through thermal balances between anomalous wind- 
driven meridional heat advection in the upper layer of the ocean and the loss of anomalous SST-induced sensible-plus-latent heat to the overlying troposphere.

The question posed in this study is whether covarying SST and MSW anomalies associated with the ACW, and its proposed coupled nature, allow the ACW to influence autumn-winter temperature and precipitation over New Zealand. This is certainly suggested by the fact that New Zealand lies directly in the path of the ACW as it propagates from the Indian Ocean into the Pacific Ocean during its global traverse around the Southern Ocean. If the answer to this question is in the affirmative, then the obvious next question to ask is whether the very regular eastward propagation of the ACW around the Southern Ocean can be used to predict New Zealand autumn-winter temperature and precipitation anomalies 1-2 yr into the future.

To answer these and related questions, we begin by demonstrating that autumn-winter mean temperature and precipitation anomalies at individual station locations over New Zealand are organized into large-scale patterns. This is accomplished by applying complex empirical orthogonal function (CEOF) analysis to the collection of 21 temperature and 33 precipitation records at stations located around New Zealand. We find that over $65 \%$ of the interannual variance in the aggregate can be explained by a single dominant CEOF mode for each variable. This allows us to use CEOF time sequences as indices for New Zealand temperature and precipitation in comparison with other climate variables. Next, we correlate these indices with interannual SST anomalies over the western South Pacific Ocean to infer what influence the latter has on the former. We find significant correlations that are consistent with the covarying SST and MSW anomalies associated with the ACW (White et al. 1998), allowing us to propose a number of thermodynamical effects linking the ACW to New Zealand temperature and precipitation during autumn-winter. Next, we construct a statistical climate prediction system capable of predicting patterns of anomalous SST patterns linked statistically to New Zealand temperature and precipitation indices. This climate prediction system is two tiered: during the first tier, the regular eastward propagation of the ACW allows SST anomaly patterns in the vicinity of New Zealand to be hindcasted at lead times of 1-2 yr; during the second tier, the statistical inference between these SST anomaly patterns and New Zealand temperature and precipitation indices allows the latter to be hindcasted as well. We go on to demonstrate that the predictability of autumnwinter temperature and precipitation over New Zealand is significantly better than can be achieved either by chance or by persistence.

\section{Data and methods}

We rely upon monthly mean temperature (precipitation) measurements made at 21 (33) stations around
New Zealand from 1982 to 1995 (Fig. 1). These records extend back before 1950 at most stations, but we are restricted in this study by the availability of SST data in the Southern Ocean after 1981 (see below). In the present study, we work only with individual autumnwinter averages of temperature and precipitation at each station because of the expected influence that seasonal SST anomalies have upon seasonal MSW anomalies during this time (White et al. 1998). This yields 14point time sequences from 1982 to 1995 . Next, we compute the 14-yr autumn-winter mean at each station and subtract it from the individual autumn-winter means, yielding interannual anomalies. At each station location, root-mean-square (rms) estimates of interannual autumn-winter anomalies are displayed in Fig. 1, showing where interannual autumn-winter variability is relatively weak and strong. For temperature, rms differences are remarkably similar, ranging from $0.4^{\circ}$ to $0.7^{\circ} \mathrm{C}$ for stations on the coastal plains and reaching as high as $1.3^{\circ} \mathrm{C}$ in the mountain ranges of South Island. For precipitation, rms differences are larger in the mountain ranges of both North and South Island (i.e., $>40 \mathrm{~mm}$ ) than on the coastal plains (i.e., $<20 \mathrm{~mm}$ ).

We also rely upon the SST dataset analyzed monthly on a $2^{\circ}$ latitude-longitude grid at the National Centers for Environmental Prediction (NCEP) in the United States (Reynolds and Marsico 1993). We utilize that portion of NCEP SST dataset extending from $0^{\circ}-80^{\circ} \mathrm{S}$ for $14 \mathrm{yr}$ from 1982 to 1995 . This dataset derives from a blended mixture of in situ measurements collected by volunteer observing ships and Advanced Very High Resolution Radiometer (AVHRR) satellite measurements. In the Southern Ocean from $40^{\circ} \mathrm{S}-70^{\circ} \mathrm{S}$, in situ measurements have always been relatively sparse, and since satellite AVHRR became available only after 1981, this NCEP SST dataset is not reliable in the Southern Ocean prior to 1982. In the present study, we initially compute SST anomalies about the mean annual cycle, but we subsequently bandpass filter them with an admittance window (Kaylor 1977) that allows periods of 3-6 yr to be isolated from annual and biennial climate signals on the high-frequency side and decadal climate signals and trends on the low-frequency side. This follows the methodology used by White and Peterson (1996) to reveal the ACW in the Southern Ocean.

We also rely upon MSW and zonal surface wind (ZSW) datasets analyzed monthly on a $2^{\circ}$ latitude-longitude grid from the NCEP reanalysis (Kalnay et al. 1996). These surface wind datasets are derived from the synthesis of in situ and satellite datasets within the NCEP reanalysis model. These datasets extend from the equator to $80^{\circ} \mathrm{S}$ for the $14-\mathrm{yr}$ period from 1982 to 1995 and are treated here in the same manner as the interannual SST anomalies discussed previously. This yields interannual ZSW and MSW anomalies that capture climate variability with period scales of 3-6 yr associated with the ACW (White and Peterson 1996). 


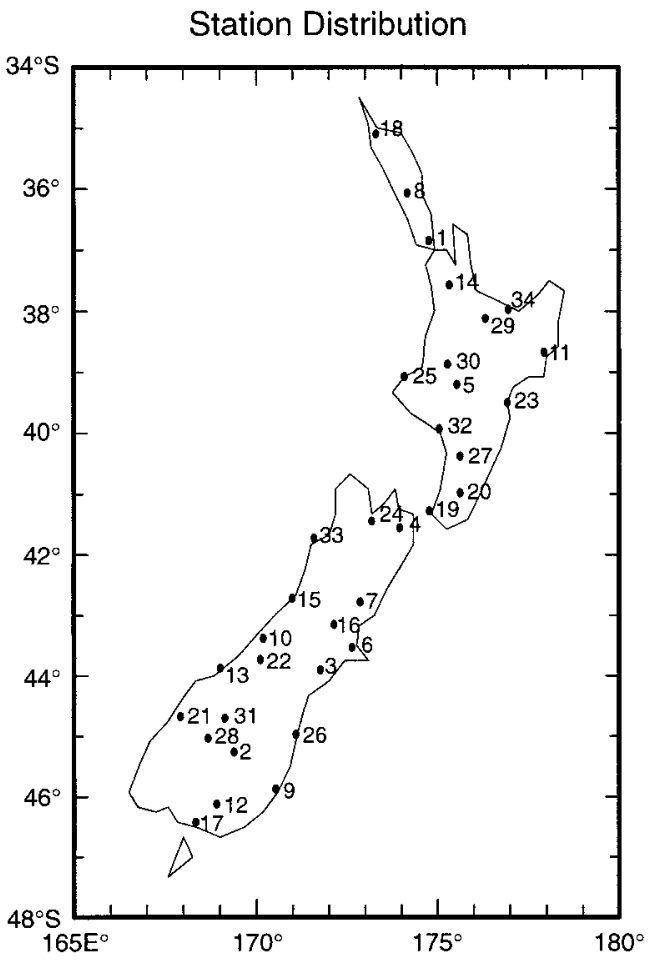
1. Albert Park
2. Alexandra
3. Ashburton
4. Blenheim
5. Chateau-Mt Ruapehu
6. Christchurch
7. Culverden (Amuri)
8. Dargaville
9. Dunedin
10. Franz Josef
11. Gisborne Airport
12. Gore
13. Haast
14. Hamilton Airport
15. Hokitika Airport
16. Hororata/Darfield
17. Invercargill

Station Names

18. Kaitaia Airport

19. Kelburn

20. Masterton

21. Milford Sound

22. Mt Cook-Hermitage

23. Napier

24. Nelson Airport

25. New Plymouth

26. Oamaru

27. Palmerston North

28. Queenstown

29. Rotorua

30. Taumarunui

31. Wanaka

32. Wanganui

33. Westport Airport

34. Whakatane

RMS of Autumn-Winter Temperature $\left({ }^{\circ} \mathrm{C}\right)$

RMS of Autumn-Winter Precipitation ( $\mathrm{mm}$ )
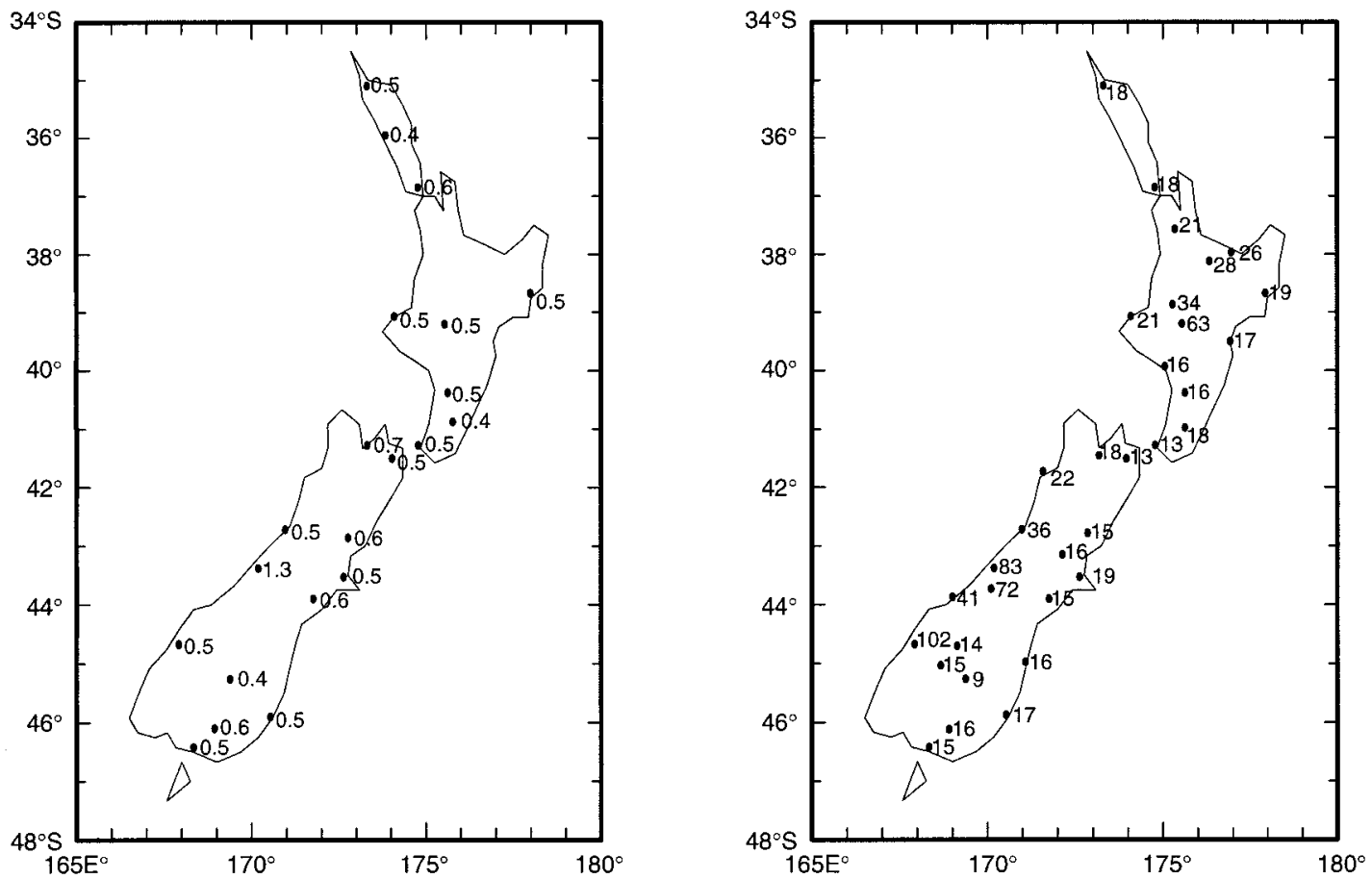

FIG. 1. (top) The locations of 33 (21) stations where precipitation (temperature) was measured over New Zealand from 1982 to 1995, and the legend that gives the name and number for each station. (bottom) The rms of autumn-winter variability in temperature (left) and precipitation (right) at each station. Temperature variability is given in ${ }^{\circ} \mathrm{C}$ and precipitation variability is given in $\mathrm{mm}$. 


\section{Patterns of New Zealand temperature and precipitation anomalies during autumn-winter}

Earlier, Salinger (1980a,b) established that monthly New Zealand temperature and precipitation anomalies could be represented with relatively few empirical orthogonal function modes. Here, we demonstrate that interannual variability in New Zealand autumn-winter temperature and precipitation can be represented by a single dominant mode of CEOF analysis. We conduct CEOF analysis (Preisendorfer and Mobley 1988) on autumn-winter temperature records at 21 stations over New Zealand from 1982 to 1995 , yielding a first mode that explains $65 \%$ of the total interannual variance (Fig. 2 , top). This mode reveals a 4-6-yr quasi periodicity in these records that is consistent with that of $\mathrm{ACW}$ in the Southern Ocean (White and Peterson 1996). Real and imaginary component time sequences are orthogonal to each other, as required by the CEOF analysis. The corresponding spatial patterns find temperature weights in the real component to be positive over most of New Zealand, with most magnitudes ranging from 1.0 to 3.0. The spatial pattern of the imaginary component finds temperature weights to be positive over most of New Zealand as well, but with most magnitudes less than 1.0, much weaker than in the real component. This indicates that the imaginary component of the CEOF represents little of the variance accounted for by the complex pair. As such, New Zealand autumn-winter temperature variability can be represented by a standing wave component, given here by the real component of the complex pair.

CEOF analysis of autumn-winter precipitation records at 33 stations over New Zealand from 1982 to 1995 yields a first mode explaining $76 \%$ of the total interannual variance (Fig. 2, bottom). This mode reveals a persistent 3-4-yr quasi periodicity in these records that is consistent with that of the ACW in the Southern Ocean. Real and imaginary component time sequences are orthogonal to each other. The corresponding spatial pattern finds precipitation weights in the real component to be positive over most New Zealand, with magnitudes greater than 0.5 in the mountains, larger than on the coastal plains (i.e., <0.5). The spatial pattern of the imaginary component also finds precipitation weights positive over most of New Zealand, but much larger in the mountains and along the west coast of the southern island (i.e., $>1.0$ ) than on the coastal plains (i.e., $<0.5$ ).

The relative parity among the weights in the real and imaginary components of the precipitation CEOF mode indicates that New Zealand autumn-winter precipitation anomalies have a greater propagational character associated with them than do New Zealand autumn-winter temperature anomalies. Since the real component lags the imaginary component by approximately $1 \mathrm{yr}$, larger positive weights in the western and central mountain ranges of the southern island in the imaginary component weaken and propagate equatorward to the coastal plains of the northern island in the real component $1 \mathrm{yr}$ later. As we shall demonstrate below, this eastward and equatorward propagation is consistent with the direction of propagation in SST anomalies (and atmospheric circulation anomalies) associated with the ACW in the vicinity of New Zealand.

In the CEOF time sequences in Fig. 2, the timescales for New Zealand autumn-winter temperature variability are longer (i.e., 4-6 yr) than those for New Zealand autumn-winter precipitation variability (i.e., 3-4 yr). This indicates that processes relating the ACW to New Zealand temperature variability are different from those relating it to New Zealand precipitation variability. As we shall demonstrate below, the ACW influences New Zealand temperature in one way, while it appears capable of influencing New Zealand precipitation in three different ways. This may account for the more frequent variability in New Zealand precipitation compared to New Zealand temperature.

\section{Propagation of regional SST anomalies associated with the $\mathrm{ACW}$}

Extended empirical orthogonal function (EEOF) analysis (Graham et al. 1987) of interannual SST anomalies from 1982 to 1995 from $0^{\circ}$ to $80^{\circ} \mathrm{S}$ yields a lag sequence of maps that allows the average eastward propagation of the ACW to be animated over the entire Southern Hemisphere (Fig. 3). This lag sequence extends over 48 months and explains $72 \%$ of total interannual variance from 1982 to 1995 associated with 3-6-yr period variability. It also allows the eastward propagation of the ACW in the Southern Ocean to be compared with evolution of ENSO in the tropical ocean. Recently, Qiu and Jin (1997) demonstrated that the global eastward propagation of the ACW occurs independently of ENSO, the latter characterized by global zonal wavenumber 1, while the former is characterized by global zonal wavenumber 2. Yet, Peterson and White (1998) found tropical ENSO influencing the ACW in the central and eastern Pacific sector of the Southern Ocean, and the ACW in turn influencing ENSO in the tropical South Atlantic and South Indian Oceans, both acting through slow meridional oceanic teleconnections that follow the general surface circulation. Peterson and White (1998) also observed ENSO signals propagating eastward across the tropical Indian and Pacific Oceans at twice the speed (in degrees longitude per year) of the ACW across the Indian and Pacific sectors of the Southern Ocean.

The way in which global properties of the ACW impact SST anomalies in the vicinity of New Zealand can be examined in this EEOF lag sequence (Fig. 3). It displays warm and cool SST weights associated with the ACW propagating eastward over the latitude range from $30^{\circ}$ to $70^{\circ} \mathrm{S}$ in the Indian and Pacific sectors of the Southern Ocean. Since New Zealand is directly in the path of this eastward propagation, this suggests that year-to-year changes in New Zealand climate (e.g., its 


\section{CEOF of Temperature $(65 \%)$}
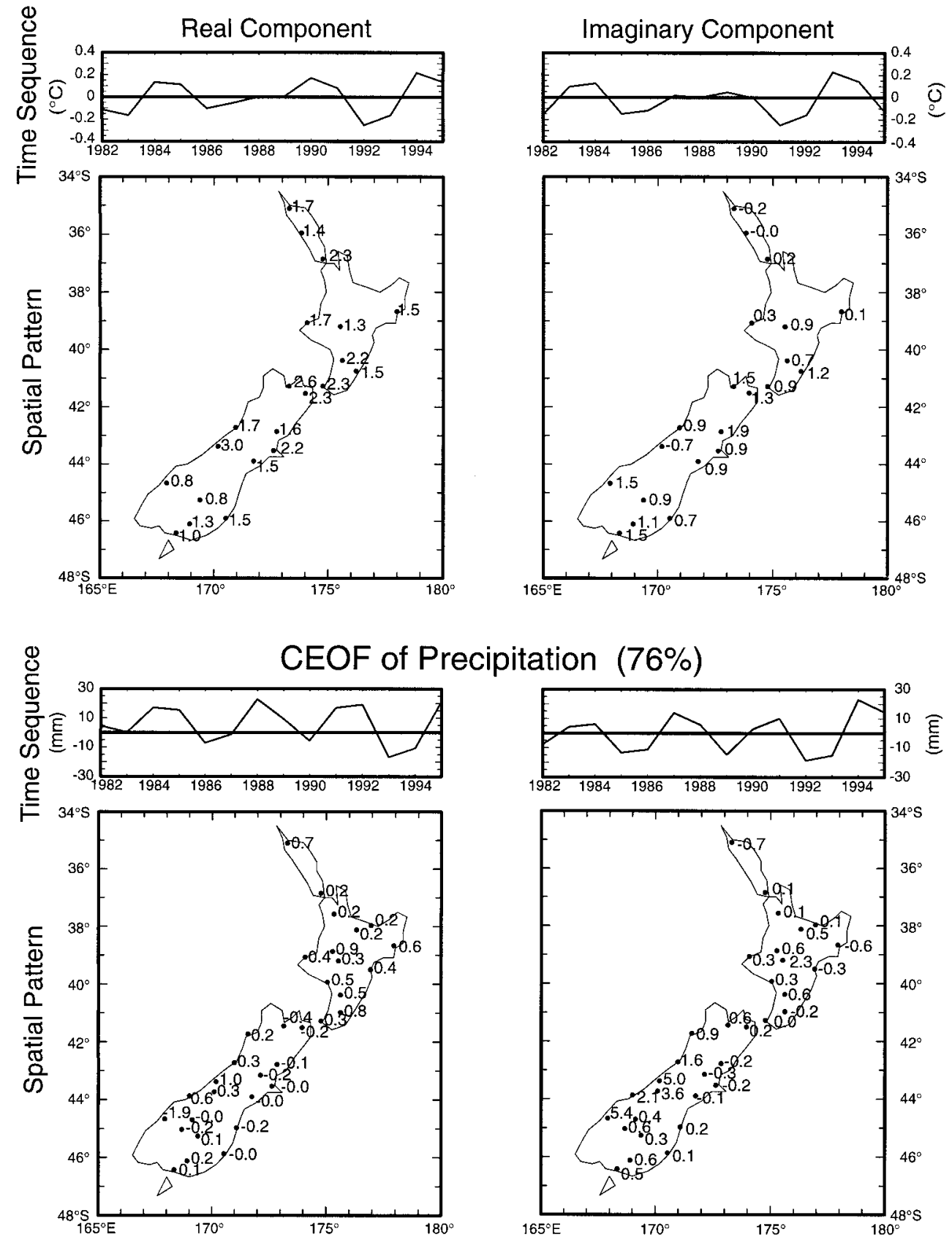

FIG. 2. (top) Real and imaginary components of the dominant CEOF mode of autumn-winter temperatures for the 21 stations over New Zealand from 1982 to 1995 . This mode explains 65\% of the total interannual variance in temperature experienced collectively by the 21 stations. (bottom) Real and imaginary components of the dominant CEOF mode of autumn-winter precipitation for the 33 stations over New Zealand from 1982 to 1995 . This mode explains $76 \%$ of the total interannual variance experienced by the 33 stations. Each component has a time sequence that modulates the corresponding spatial pattern, extending from 1982 to 1995. Individual estimates explained by the components of this dominant CEOF mode can be recovered by multiplying station values times the estimate in the time sequences at any particular time to obtain autumn-winter anomalies in ${ }^{\circ} \mathrm{C}$ for temperature and $\mathrm{mm}$ for precipitation. 


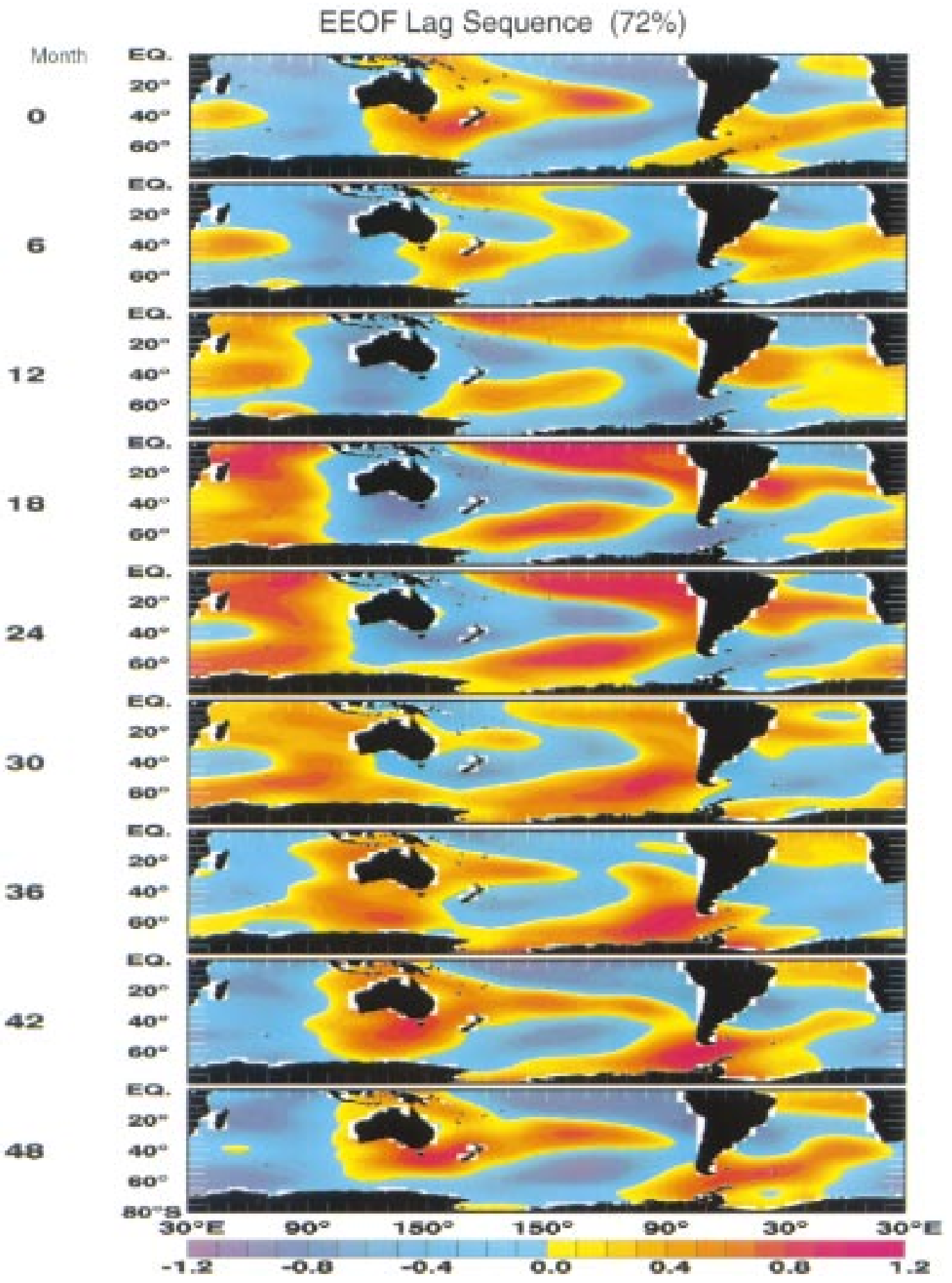

FIG. 3. The lag sequence of maps associated with the dominant EEOF mode of interannual SST anomalies computed from the NCEP reanalysis from 1982 to 1995 , with each map extending globally over the Southern Hemisphere from $0^{\circ}$ to $80^{\circ} \mathrm{S}$. This lag sequence extends over 48 months, or approximately one complete cycle of the ACW in the Southern Ocean, with individual positive and negative weights propagating half the distance around the Southern Ocean. Contour intervals are given by the color bar, with blue-purple colors indicating negative weights and yellowred colors indicating positive weights. The eastward propagation of the ACW can be seen by following positive or negative weights in time lag as they propagate mostly eastward over the 48 months. 
autumn-winter temperature and precipitation) are influenced by the covarying SST and MSW anomalies associated with the ACW propagating eastward from the South Indian Ocean, south of Australia, and on past New Zealand into the central South Pacific Ocean.

This lag sequence also reveals subtropical SST weights north of New Zealand appearing spontaneously and then propagating poleward to the east of New Zealand. Peterson and White (1998) explained this apparent spontaneous generation between $20^{\circ}$ and $30^{\circ} \mathrm{S}$ in terms of a local anomalous Hadley cell driven by SST anomalies of opposite sign on the equator associated with ENSO. The Hadley circulation generates air-sea heat flux anomalies that drive these subtropical SST anomalies, which are subsequently advected toward the southeast by the general surface circulation of the ocean. While this advective influence for the most part bypasses New Zealand to the east, it may have an influence upon New Zealand precipitation.

\section{Associations between New Zealand autumn-winter temperature and precipitation indices and regional SST anomalies}

We seek to determine whether autumn-winter temperature and precipitation anomalies over New Zealand are related to regional interannual SST anomalies. This is accomplished by correlating the real and imaginary components of CEOF time sequences in Fig. 2, representing real and imaginary New Zealand temperature and precipitation indices, with interannual SST anomalies from 1982 to 1995 used in the construction of the EEOF lag sequence in Fig. 3. Resulting spatial distributions of these correlations (Fig. 4) yield particular patterns of interannual SST anomalies that covary with these indices of New Zealand autumn-winter temperature and precipitation indices. Moreover, these correlation patterns give clues as to the thermodynamics linking island and regional oceanic and atmospheric climate variability.

The distribution of correlation associated with the real New Zealand temperature index (Fig. 4, top) finds it correlated with interannual SST anomalies adjacent to New Zealand and extending eastward from North Island. Not surprisingly, this indicates that New Zealand autumn-winter temperatures are brought to the same autumn-winter temperatures as the surrounding ocean, most probably through sensible heat exchange from the ocean to the atmosphere. This physical interpretation is consistent with the coupling dynamics of the ACW proposed by White et al. (1998). We do not correlate the imaginary New Zealand temperature index with regional SST anomalies, since it represents so little of the interannual variance. The shaded box in this top panel defines the area-average SST index that correlates best with the real New Zealand temperature index.

The distributions of correlation associated with real and imaginary New Zealand precipitation indices are

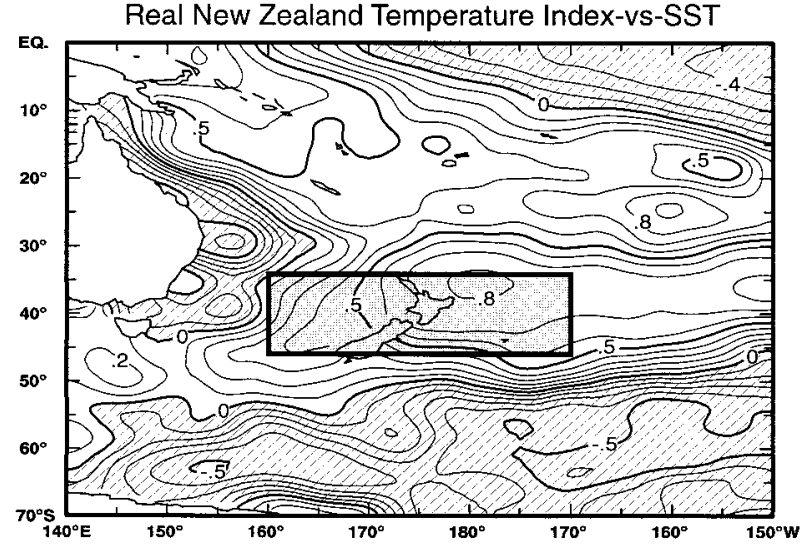

Real New Zealand Precipitation Index-vs-SST

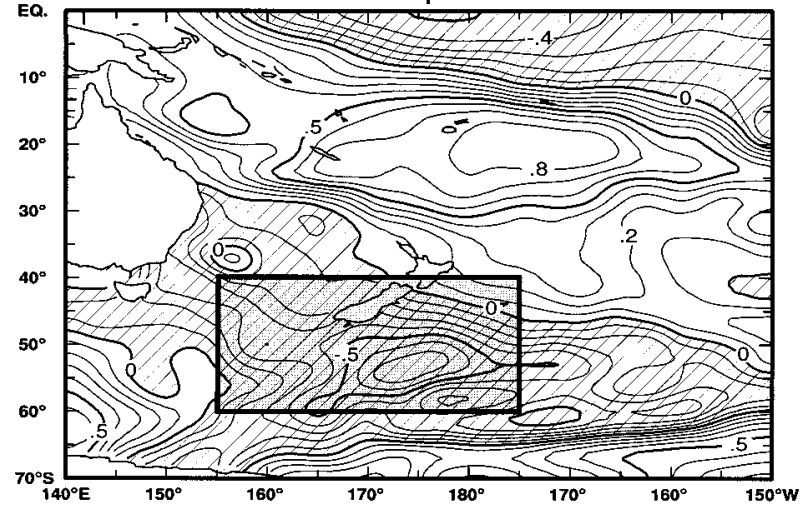

Imaginary New Zealand Precipitation Index-vs-SST

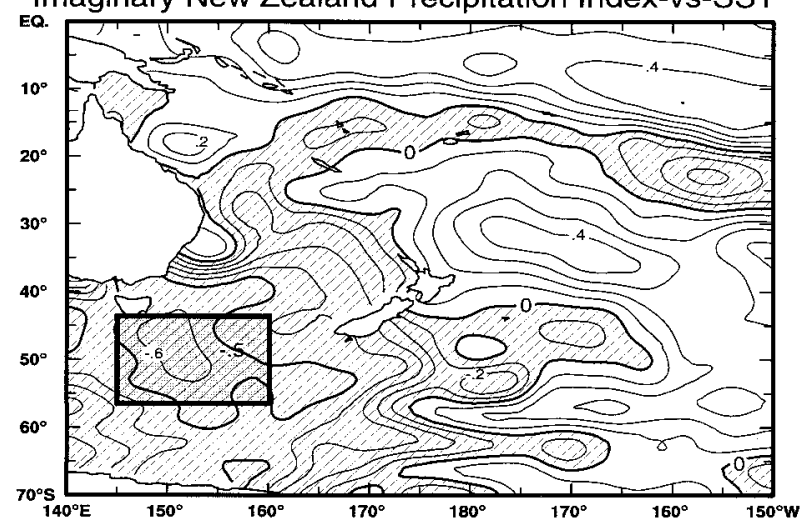

FIG. 4. (top) Distribution of correlation between the time sequence for the real New Zealand temperature index and interannual SST anomalies over the western South Pacific Ocean. Only the correlation map for the real index is presented, as the imaginary index carries so little of the interannual variance (see Fig. 2). (middle and bottom) Distributions of correlation between time sequences for real and imaginary New Zealand precipitation indices and interannual SST anomalies over the western South Pacific Ocean. Negative (positive) correlations in each panel are shaded (unshaded). Contour intervals are 0.1 units of correlation. Shaded boxes delineated by heavy black lines identify regions where area-average SST anomalies (i.e., SST indices) correlate best with New Zealand temperature and precipitation indices. 
given in the middle and bottom panels of Fig. 4. The real index is correlated with positive SST anomalies directly north of New Zealand between $10^{\circ}$ and $30^{\circ} \mathrm{S}$ and negative SST anomalies directly south of New Zealand between $40^{\circ}$ and $60^{\circ} \mathrm{S}$. The imaginary index is correlated with positive SST anomalies northeast of New Zealand and negative SST anomalies southwest of New Zealand. Earlier in Fig. 2, we observed the imaginary index of New Zealand precipitation leading the real index by approximately $1 \mathrm{yr}$; in Fig. 4, the displacement of positive and negative correlations from the imaginary index to the real index indicates an eastward propagation south of New Zealand, a weak poleward propagation in the Tasman Sea west of New Zealand, and a weak equatorward propagation in the western South Pacific Ocean east of New Zealand. This is consistent with the predominantly eastward propagation of the ACW in Fig. 3. The shaded boxes in the middle and bottom panels of Fig. 4 define area-average SST indices, which correlate best with real and imaginary New Zealand precipitation indices, respectively.

If we apply what we have learned from White et al. (1998) about the thermodynamical equilibrium between interannual SST and MSW anomalies associated with the ACW (refer back to the introduction), these correlation patterns suggest that New Zealand autumn-winter precipitation anomalies fluctuate in response to the slow eastward propagation of atmospheric circulation anomalies in the ACW from one autumn-winter to the next. We establish the pattern of this anomalous autumn-winter atmospheric circulation by computing the distributions of correlation between real and imaginary New Zealand precipitation indices (Fig. 2, bottom panels) and interannual ZSW and MSW anomalies over the western South Pacific Ocean. These correlations are displayed as vectors in Fig. 5 and are overlaid onto the scalar correlations with SST repeated from the middle and bottom panels of Fig. 4; this allows the phase relationship between SST, MSW, and ZSW anomalies to be inferred. As expected from White et al. (1998), both panels in Fig. 5 display poleward (equatorward) MSW anomalies over warm (cool) SST anomalies. From the upper panel of Fig. 5, we can infer that warm (cool) SST anomalies north (south) of New Zealand are associated with intense anomalous low-level wind convergence over New Zealand. From this, we can presume that this wind convergence is also associated with anomalous low-level moisture flux convergence, consistent with the positive precipitation weights associated with the real New Zealand precipitation index (Fig. 2, bottom left panel). From the lower panel of Fig. 5, we can infer that warm (cool) SST anomalies northeast (southwest) of New Zealand are associated with anomalous cyclonic atmospheric circulation over New Zealand (with an anomalous low sea level pressure center displaced approximately $10^{\circ}$ latitude south of New Zealand). Since Kidson and Gordon (1996) found autumn-winter precipitation related to extratropical cyclone activity over
New Zealand, this is consistent with the positive precipitation weights associated with the complex New Zealand precipitation index (Fig. 2, bottom right panel). Moreover, since these latter positive precipitation weights are much larger in the mountain ranges of South Island than on the coastal plains, another precipitation mechanism is suggested, that is, anomalous orographic influences resulting from positive westerly wind anomalies incident upon these southern mountain ranges (Sturman and Tapper 1996), indicated in the lower panel of Fig. 5.

The major point to emphasize here is that interannual MSW and ZSW anomalies appear to be in thermodynamic equilibrium with the underlying interannual SST anomalies during autumn-winter, as simulated in the model ACW by White et al. (1998). Consistent with this, autumn-winter temperature anomalies over New Zealand come into thermal balance with contemporaneous SST anomalies, the latter slowly propagating eastward into the vicinity of New Zealand in association with the ACW, heating New Zealand temperature through anomalous SST-induced sensible heat flux from the upper ocean into the lower troposphere. Also consistent with this, autumn-winter precipitation anomalies over New Zealand are in hydrologic balance with contemporaneous atmospheric circulation anomalies, the latter in thermodynamic balance with the pattern of SST anomalies around New Zealand, as simulated in the model ACW by White et al. (1998). Three different precipitation mechanisms are indicated, acting either in phase or in quadrature, that is, anomalous low-level moisture flux convergence over New Zealand, anomalous extratropical cyclonicity over New Zealand, and anomalous westerly winds producing anomalous orographic precipitation over the mountain ranges of South Island.

\section{Inferring New Zealand autumn-winter temperature and precipitation indices from regional SST indices}

We now determine whether statistical inferences between New Zealand autumn-winter temperature and precipitation indices and regional SST indices are reliable enough to estimate the former in terms of the latter. This is accomplished by computing the linear regression between real and imaginary New Zealand autumn-winter temperature and precipitation indices in Fig. 2 and their corresponding area-average SST indices computed over the shaded boxes surrounding regions of maximum correlation in Fig. 4. With regard to New Zealand precipitation, note that we have ignored regions of high correlation east and north of New Zealand, focusing on the SST indices west and south of New Zealand that are more directly influenced by the slow eastward propagation of the ACW. As Peterson and White (1998) have demonstrated, interannual SST anomalies 

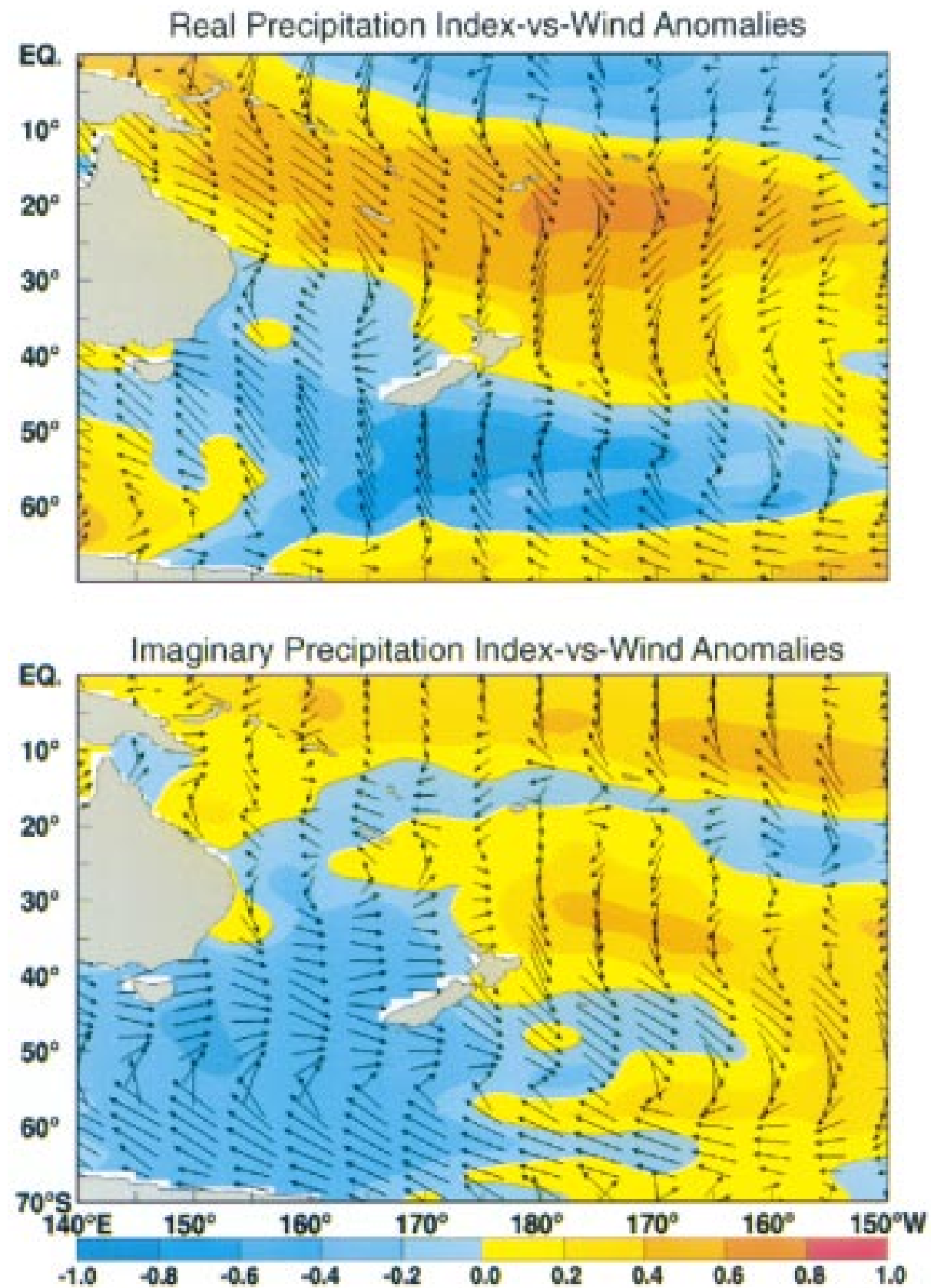

FIG. 5. Distributions of correlation between time sequences of real and imaginary New Zealand autumnwinter precipitation indices and interannual ZSW and MSW anomalies over the western South Pacific Ocean, displayed in the form of a vector. These wind correlation vectors are overlaid onto the scalar SST correlation from the middle and bottom panels in Fig. 4. Contour intervals for the scalar SST correlation are given by the color bar, with blue-purple colors indicating negative SST correlation and yellow-red colors indicating positive SST correlation. Correlations vectors to the north (east) indicate positive correlation in the MSW (ZSW) component.

north and east of New Zealand are influenced by tropical ENSO, as discussed in the last paragraph of section 4 .

The scatterplot and linear regression (Snedecor and Cochran 1980) between the real New Zealand temperature index and its corresponding SST index (Fig. 6a), finds the latter able to infer the sign of the former during 12 of the $14-y r$ record, explaining $50 \%$ of the total interannual variance. Scatterplots and linear regressions between real (imaginary) New Zealand precipitation indices and their corresponding SST indices [Fig. 6b (Fig. 

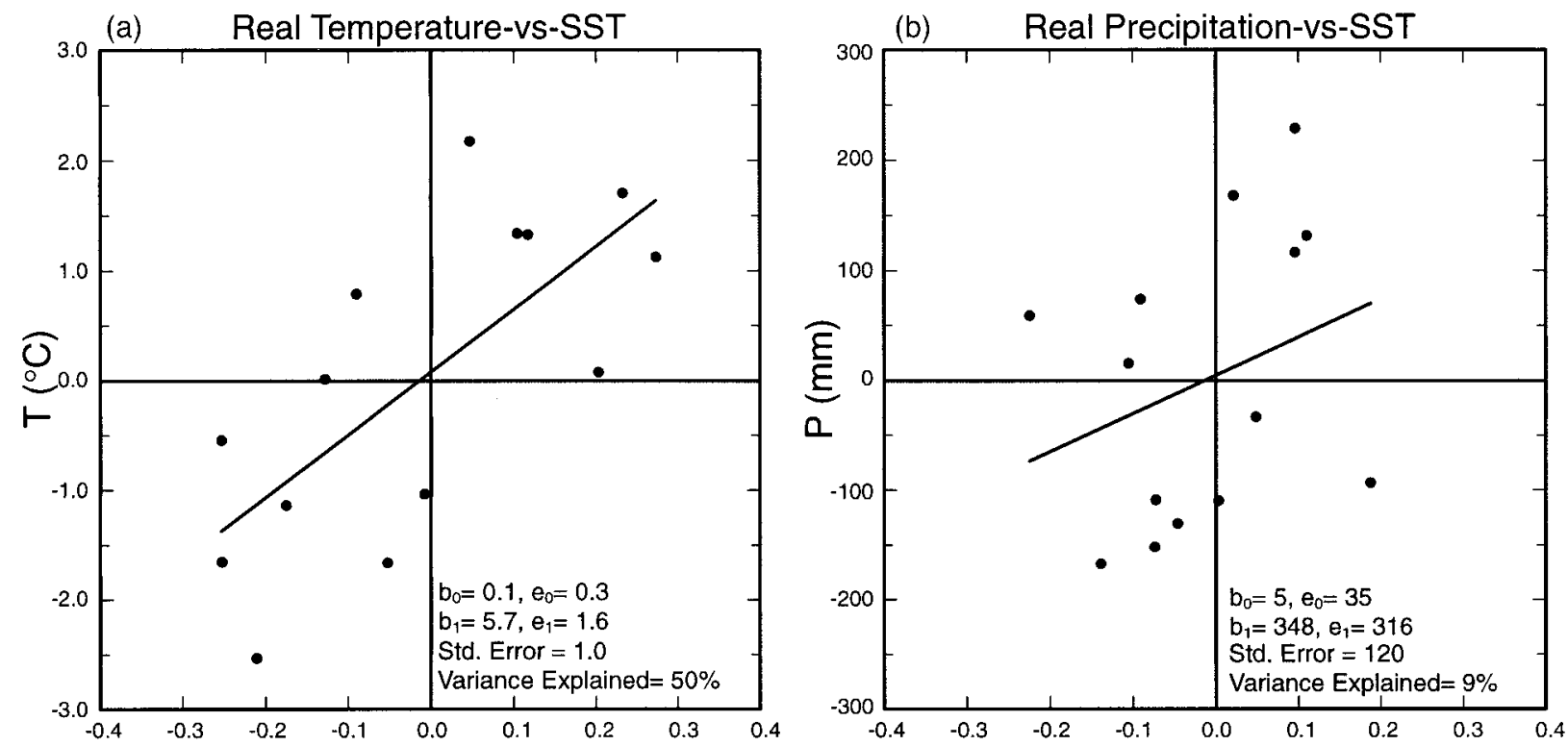

(c) Imaginary Precipitation-vs-SST

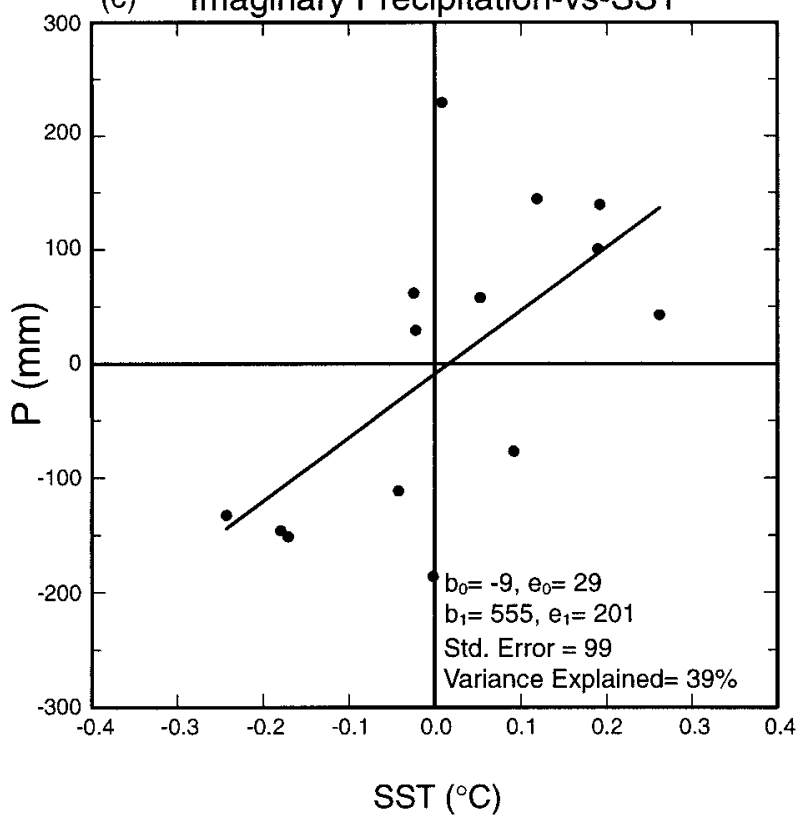

(d) Composite Precipitation-vs-SST

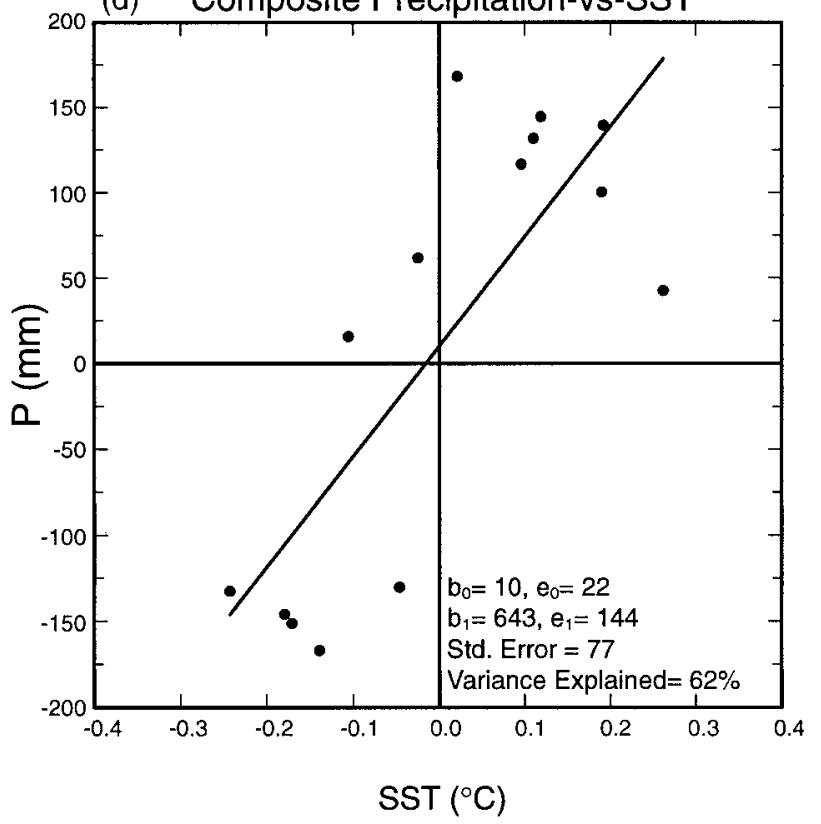

FIG. 6. (a) Scatter diagram between the SST index for the shaded box given in the top panel of Fig. 4 and the corresponding time sequence for the real New Zealand autumn-winter temperature index given in the top left panel of Fig. 2. (b) Scatter diagram between the SST index for the shaded box given in the middle panel of Fig. 4 and the corresponding time sequence for the real New Zealand autumn-winter precipitation index given in the bottom left panel of Fig. 2. (c) Scatter diagram between the SST index for the shaded box given in the bottom panel of Fig. 4 and the corresponding time sequence for the imaginary New Zealand autumn-winter precipitation index given in the bottom right panel of Fig. 2. (d) Scatter diagram between a composite New Zealand precipitation index and corresponding SST indices, using either real or imaginary versions of the index depending upon which time sequence has the largest absolute value in the corresponding SST index at any particular time. Linear regression applied to these scatter diagrams yields the percentage of interannual variance in New Zealand temperature and precipitation indices that can be nowcasted by regional SST indices. See text for further details.

$6 c)]$ finds the latter able to infer the sign of the former during 8 (11) yr of the 14-yr record, but explaining only $9 \%(39 \%)$ of the total interannual variance.

We can improve this statistical inference of New Zealand precipitation by making use of the propagating sig- nal contained in the real and imaginary components of the CEOF, computing a composite scatter diagram using either the real or the imaginary version, whichever has the largest absolute value for its corresponding SST index (Fig. 6d). This provides greater flexibility for in- 
ferring New Zealand precipitation indices from corresponding SST indices; that is, we infer New Zealand precipitation indices at any particular time with the largest of the two SST indices, one or the other of which will be dominant at that time. As can be seen, this latter development yields much better regression between this composite New Zealand precipitation index and corresponding SST indices, that is, with the sign of the New Zealand index inferred from the SST index during 12 of the 14-yr record, explaining $62 \%$ of the total interannual variance. This statistical inference is better than that for the New Zealand temperature index.

\section{Predicting regional SST indices around New Zealand from eastward propagation of the ACW}

Having established the statistical inference relating New Zealand autumn-winter temperature and precipitation indices to regional SST indices during autumnwinter in Fig. 6, and having established in Fig. 3 that interannual SST anomalies in the vicinity of New Zealand are associated with the slow eastward propagation of the ACW (White and Peterson 1996), the next question to ask is whether this eastward propagation can be used to predict these regional SST indices and, hence, New Zealand autumn-winter temperature and precipitation indices 1-2 yr into the future.

To answer this question, we construct the following statistical climate prediction system. First, we characterize the eastward propagation of the ACW past New Zealand with the SST EEOF lag sequence in Fig. 3. Since we are interested in predicting up to $2 \mathrm{yr}$ into the future, and since the EEOF lag sequence is $4 \mathrm{yr}$ in duration, we need to determine at any particular time what 2-yr portion of the EEOF lag sequence provides the best fit with the previous 2 -yr portion of the time sequence of SST anomaly maps; then, the 2-yr portion of the EEOF lag sequence that extends into the future gives the best estimate as to how the ACW will propagate into the future, assuming stationarity of the statistics. To accomplish this, we use pattern correlation analysis to provide for the best fit; but to achieve the highest hindcast skill at 1-yr lead between observed SST indices and projected SST indices from the EEOF lag sequence, we conducted a series of experiments where we subset the geographical domain over which the pattern correlations were computed. The subdomain achieving the best results extends from $30^{\circ}-55^{\circ} \mathrm{S}, 60^{\circ} \mathrm{E}-$ $170^{\circ} \mathrm{W}$ and is confined to the Southern Ocean, extending from the South Indian Ocean into the region south of Australia and on into that portion of the western South Pacific Ocean surrounding New Zealand. This is the subdomain over which the ACW is upstream from New Zealand. It does not include the subtropical region north of New Zealand, whose inclusion reduces skill markedly.

This statistical climate prediction system yields 2-yr hindcasts (i.e., light lines in Fig. 7a), which are superimposed onto the observed SST indices (i.e., heavy lines in Fig. 7a) over the 16-yr period from 1982 to 1997. For the SST index for New Zealand autumn-winter temperature (Fig. 7a, top), time sequences of 2-yr hindcasts follow the original record remarkably well from 1984 to 1992, with some difficulty in hindcasting the SST index after 1992, this associated with a general weakening in the amplitude of the SST index. This difficulty did not appear in the two SST indices associated with New Zealand autumn-winter precipitation (Fig. 7a, middle and bottom), where skill was maintained throughout the record. Quantitative estimates of hindcast skill are given in Fig. 7b, where the average hindcast skill over the $12 \mathrm{yr}$ from 1984 to 1995 is compared with that skill due to persistence for each SST index. This displays significant hindcast skill (i.e., $R=0.62$ at the $95 \%$ confidence level for 10 degrees of freedom) at $1 \mathrm{yr}$ into the future for all three of the SST indices, well beyond the 7 months or so achieved by persistence. Hindcast skill at $2 \mathrm{yr}$ into the future is insignificant.

\section{Predicting New Zealand autumn-winter temperature and precipitation from eastward propagation of the $\mathrm{ACW}$}

Having established that regional SST indices in Fig. 6 can be hindcasted $1 \mathrm{yr}$ into the future with significant skill (Figs. 7a,b), we now utilize these hindcasted SST indices to infer statistically New Zealand autumn-winter temperature and precipitation indices. This is accomplished by computing scatter diagrams like those for the linear regressions in Fig. 6, but replacing observed SST indices with hindcast SST indices for autumn-winters both 1 and 2 yr into the future (Fig. 8). Scatter diagrams for nowcasts are able to specify the observed sign during 13 (12) of the 14-yr record, explaining 50\% (62\%) of the interannual variance contained in the temperature (precipitation) indices. Scatter diagrams for hindcasts of $1 \mathrm{yr}$ into the future are able to specify the observed sign during 8 (9) of the 10-yr record, explaining $24 \%$ (74\%) of the interannual variance contained in the temperature (precipitation) indices. For the New Zealand temperature index, the $1-\mathrm{yr}$ hindcast skill is $R=0.50$, less than $R=0.71$ determined for the nowcast skill but nevertheless significant at the $90 \%$ confidence level. For the New Zealand precipitation index, the 1-yr hindcast skill is $R=0.86$, similar to the nowcast skill of $R=0.78$ and significant at the $95 \%$ confidence level. Scatter diagrams for predictions extending $2 \mathrm{yr}$ into the future fare much worse, specifying the observed sign during 6 of the $9-y r$ record, but explaining less than $12 \%$ of the interannual variance contained in these indices.

To determine how the nowcasting and 1-yr and 2-yr hindcasting of New Zealand autumn-winter temperature and precipitation indices from corresponding SST indices translate into that for autumn-winter temperature and precipitation anomalies at individual stations around 

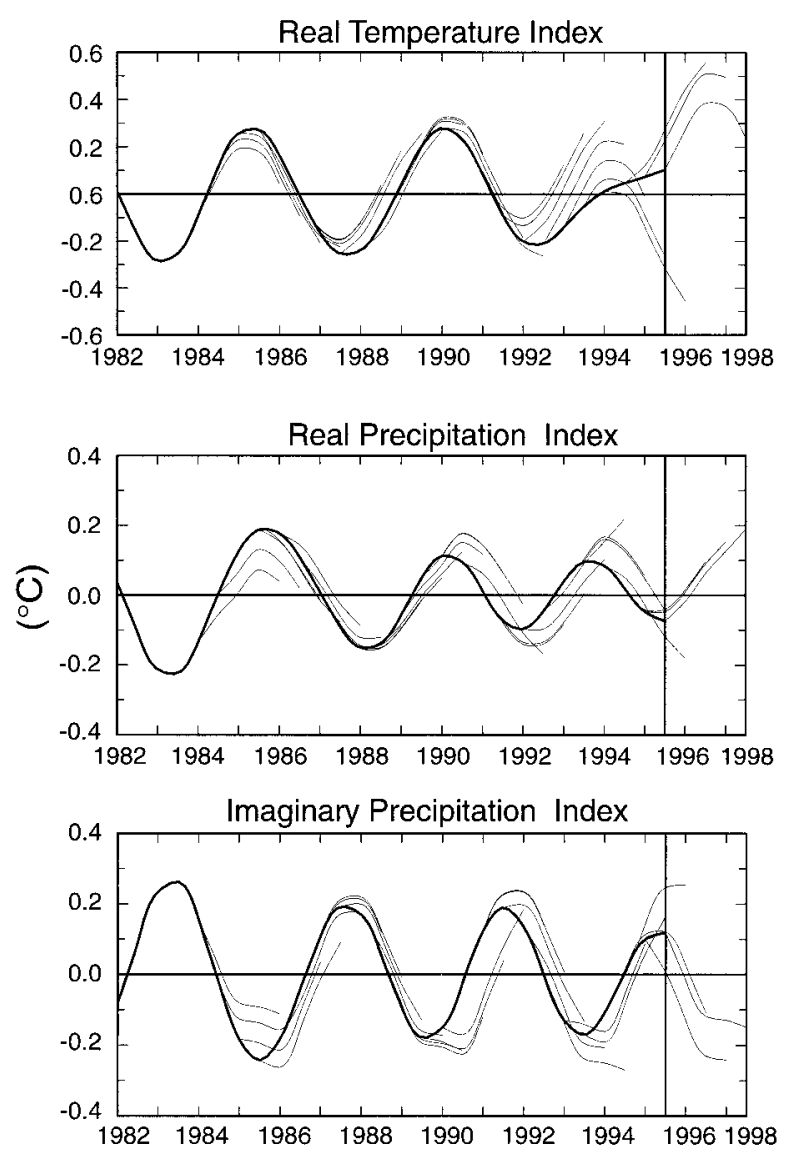

FIG. 7a. (Top) Hindcast from 1982-97 of SST indices associated with the real New Zealand autumn-winter temperature index. Hindcasts extend as light lines $2 \mathrm{yr}$ into the future from each autumnwinter period beginning in 1984. Each hindcast is based upon a best fit of the 4-yr EEOF lag sequence of SST anomalies in Fig. 3 to observed SST anomalies upstream (i.e., west) of New Zealand during the previous $2 \mathrm{yr}$. (middle and bottom) The same as above but for the real and imaginary New Zealand autumn-winter precipitation indices.

New Zealand, we compute nowcast and hindcast estimates at each station location through data reconstruction using the magnitude and phase of the CEOF modes in the scatter diagrams displayed in Fig. 8. Then, we compute the skill (i.e., correlation) between the autumnwinter nowcast-hindcast estimates against those observed for 0-, 1-, and 2-yr leads (Table 1). Correlations greater than $0.44,0.53,0.56$ are significant at the $90 \%$ confidence level for nowcasts, 1-yr hindcasts, and 2-yr hindcasts, respectively, for 14,10 , and 9 temporal degrees of freedom (Snedecor and Cochran 1980). For New Zealand temperature, 18 out of 21 stations are nowcasted significantly; 12 out of 21 stations are hindcasted significantly at 1 -yr lead; and 10 out of 21 stations are hindcasted significantly at 2-yr lead, all more than expected from chance. Those temperature stations that are significantly hindcasted at $1-\mathrm{yr}$ lead are distributed nearly uniformly over North and South Island. For New Zealand precipitation, 17 out of 33 stations are now-
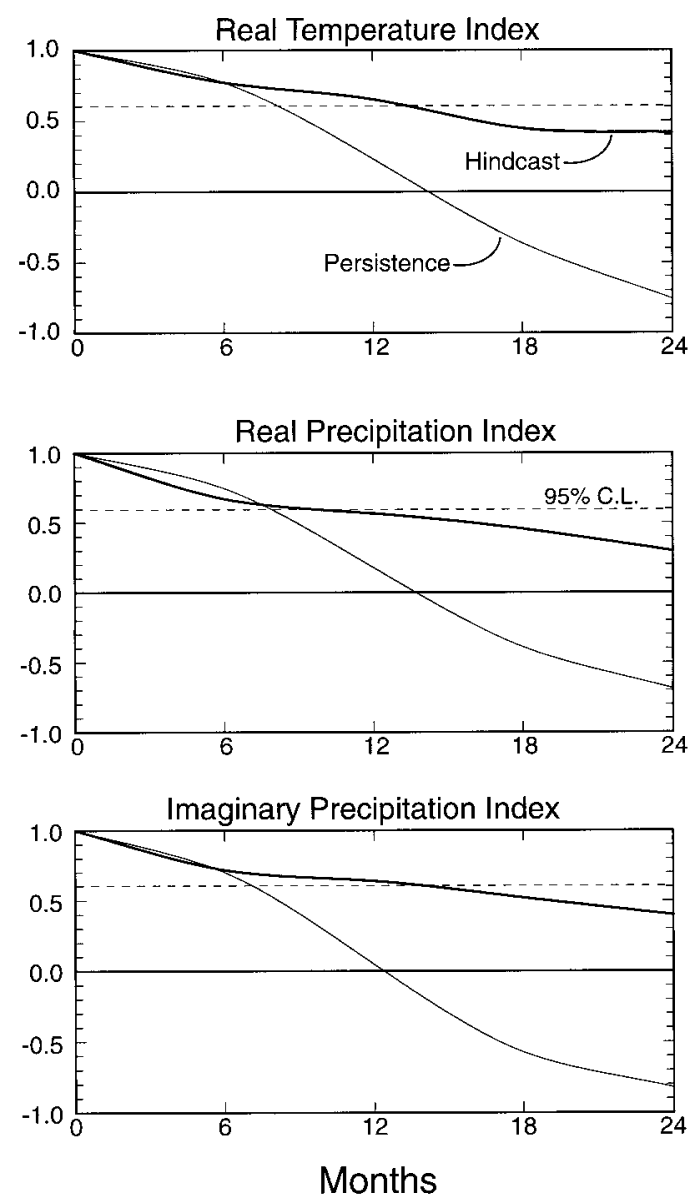

FIG. 7b. Correlations between observed and hindcasted SST indices as a function of lead extending $2 \mathrm{yr}$ into the future, compared with correlations between observed and hindcast SST indices based upon persistence. For 10 degrees of freedom, correlations greater than 0.62 are statistically significant at the $95 \%$ confidence level. Correlations associated with persistence are insignificant after approximately 7 months.

casted significantly; 14 out of 33 stations are hindcasted significantly at 1-yr lead; and only 3 out of 33 stations are hindcasted significantly at 2 -yr lead, the latter no better than expected from chance. Those precipitation stations that are significantly hindcasted at 1-yr lead are mostly located in the mountains, where the rms of variability is larger.

\section{Discussion and conclusions}

Earlier studies seeking the influence of tropical ENSO on New Zealand precipitation (Gordon 1986; Kidson and Gordon 1986) and stream flow (Moss et al. 1994) anomalies were unable to establish a consistent relationship. In the present study, we propose an explanation for this by demonstrating that New Zealand autumnwinter precipitation anomalies are significantly influenced by regional covarying SST and MSW anomalies whose pattern and evolution are dominated by the ACW 

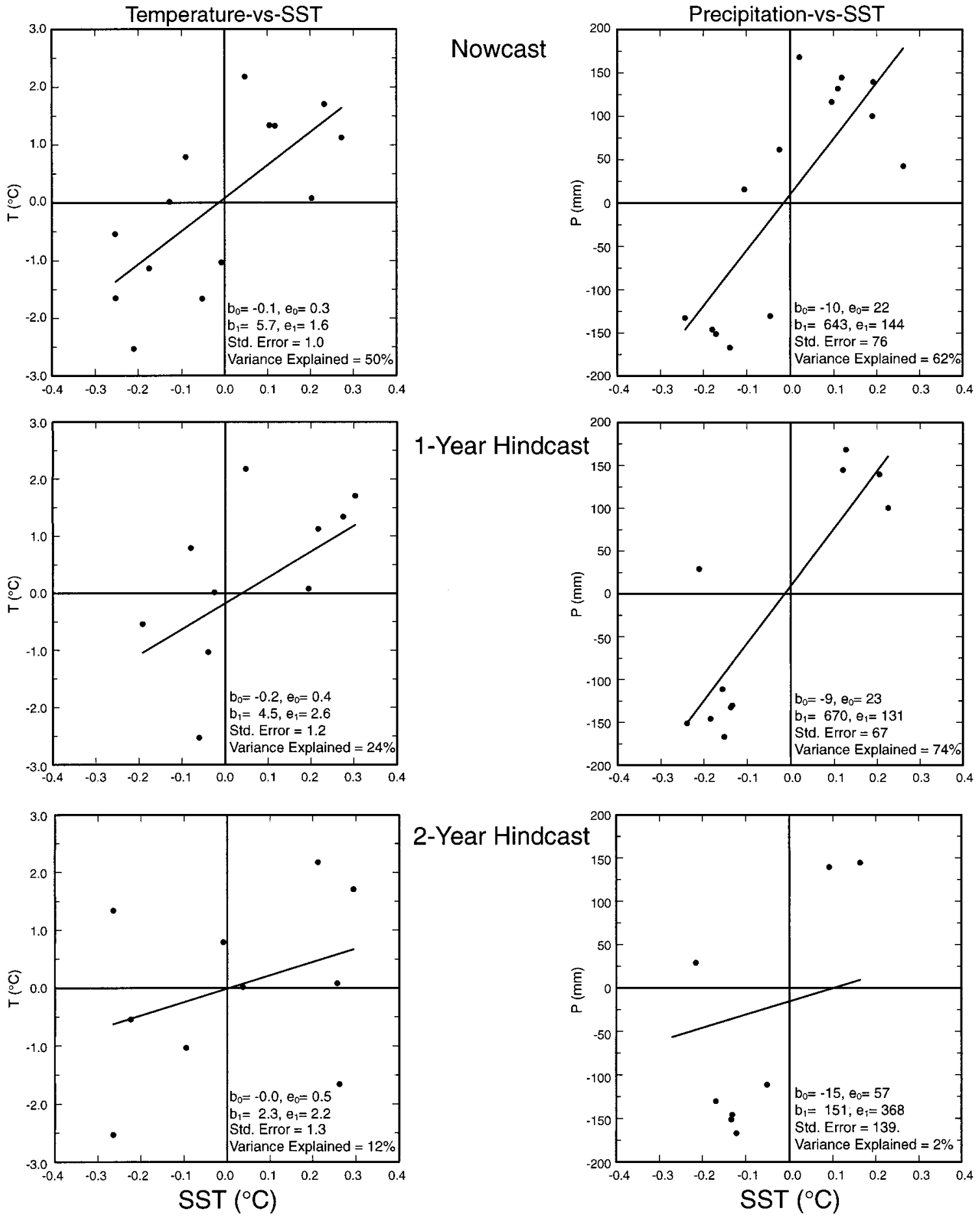

FIG. 8. (top) Scatter diagrams between the nowcast of SST indices and the New Zealand temperature and precipitation indices. (middle) Scatter diagrams between the hindcast of SST indices at 1-yr lead and the New Zealand temperature and precipitation indices. (bottom) Scatter diagrams between the hindcast of SST indices at 2-yr lead and the New Zealand temperature and precipitation indices. These scatter diagrams yield the skill (i.e., correlation) determined by linear regression with which New Zealand climate indices can be hindcasted by regional SST indices through the eastward propagation of the ACW in the vicinity and west of New Zealand. 
TABLE 1. Correlations between original and reconstructed autumnwinter (a) temperature and (b) precipitation records at individual station locations in New Zealand. The reconstructed records are nowcasted at $0-\mathrm{yr}$ lead and hindcasted at 1- and 2-yr leads from that of regional SST indices through the eastward propagation of the ACW. Correlations greater than $0.44,0.53$, and 0.55 are significant at the $90 \%$ confidence level for nowcasts, 1 -yr hindcasts, and 2-yr hindcasts, respectively, for 14, 10, and 9 temporal degrees of freedom (Snedecor and Cochran 1980).

\begin{tabular}{|c|c|c|c|c|}
\hline Station & rms & Nowcast & $\begin{array}{c}1-\mathrm{yr} \\
\text { hindcast }\end{array}$ & $\begin{array}{c}2-y r \\
\text { hindcast }\end{array}$ \\
\hline \multicolumn{5}{|c|}{ (a) New Zealand air temperature } \\
\hline Albert Park & 0.36 & 0.57 & 0.52 & 0.23 \\
\hline Alexandra & 0.24 & 0.43 & 0.23 & 0.63 \\
\hline Ashburton & 0.35 & 0.57 & 0.35 & 0.53 \\
\hline Balmoral Forest & 0.39 & 0.24 & 0.24 & 0.60 \\
\hline Blenheim & 0.40 & 0.48 & 0.43 & 0.52 \\
\hline Chateau Mt. Ruapehu & 0.33 & 0.58 & 0.73 & 0.44 \\
\hline Christchurch & 0.34 & 0.59 & 0.38 & 0.54 \\
\hline Dargaville & 0.33 & 0.24 & 0.20 & -0.22 \\
\hline Franz Josef & 0.78 & 0.72 & 0.53 & 0.77 \\
\hline Gisborne Airport & 0.36 & 0.44 & 0.58 & 0.03 \\
\hline Gore & 0.31 & 0.70 & 0.55 & 0.80 \\
\hline Hokitika & 0.30 & 0.86 & 0.73 & 0.81 \\
\hline Invercargill Aerodrom & 0.28 & 0.46 & 0.32 & 0.80 \\
\hline Kaitaia Airport & 0.30 & 0.67 & 0.65 & 0.11 \\
\hline Kelburn & 0.35 & 0.60 & 0.65 & 0.51 \\
\hline Masterton & 0.31 & 0.58 & 0.54 & 0.59 \\
\hline Milford Sound & 0.34 & 0.54 & 0.35 & 0.76 \\
\hline Musselburgh Dunedin & 0.30 & 0.54 & 0.31 & 0.61 \\
\hline Nelson & 0.44 & 0.62 & 0.56 & 0.58 \\
\hline New Plymouth & 0.27 & 0.65 & 0.58 & 0.34 \\
\hline Palmerston North & 0.36 & 0.61 & 0.55 & 0.39 \\
\hline \multicolumn{5}{|c|}{ (b) New Zealand Precipitation } \\
\hline Albert Park & 12.84 & 0.19 & -0.12 & -0.26 \\
\hline Alexandra & 5.73 & 0.82 & 0.80 & 0.56 \\
\hline Ashburton & 0.96 & -0.61 & -0.22 & -0.53 \\
\hline Blenheim & 6.95 & 0.41 & 0.13 & 0.03 \\
\hline Chateau Mt. Ruapehu & 31.22 & 0.43 & 0.60 & 0.08 \\
\hline Christchurch Gardens & 10.06 & -0.52 & 0.01 & -0.20 \\
\hline Culverden & 11.82 & -0.33 & -0.11 & -0.30 \\
\hline Darfield & 7.34 & -0.30 & 0.19 & -0.09 \\
\hline Dunedin Gardens & 11.87 & 0.72 & 0.31 & 0.37 \\
\hline Franz Josef & 68.00 & 0.59 & 0.74 & 0.23 \\
\hline Gisborne Airport & 13.33 & 0.58 & 0.49 & 0.11 \\
\hline Gore & 11.96 & 0.46 & 0.81 & 0.66 \\
\hline Haast & 28.99 & 0.55 & 0.67 & 0.81 \\
\hline Hokitika Airport & 24.23 & 0.71 & 0.68 & 0.33 \\
\hline Hororata/Darfield & 9.36 & -0.26 & 0.68 & 0.11 \\
\hline Kaitaia Airport & 14.34 & 0.61 & 0.46 & 0.03 \\
\hline Kelburn & 9.62 & 0.37 & 0.10 & -0.08 \\
\hline Milford Sound & 75.71 & 0.47 & 0.55 & -0.11 \\
\hline Mt. Cook & 49.33 & 0.77 & 0.78 & 0.30 \\
\hline Nelson Airport & 14.73 & 0.44 & 0.12 & -0.15 \\
\hline Nelson Park & 11.38 & 0.40 & 0.31 & -0.04 \\
\hline New Plymouth & 18.55 & 0.27 & 0.00 & -0.04 \\
\hline Oamaru & 8.50 & 0.83 & 0.28 & 0.54 \\
\hline Palmerston North & 11.07 & 0.37 & 0.73 & 0.45 \\
\hline Queenstown & 11.61 & 0.95 & 0.73 & 0.33 \\
\hline Rotorura & 24.66 & 0.12 & -0.03 & -0.34 \\
\hline Ruakura & 33.44 & 0.35 & 0.28 & -0.02 \\
\hline Taumarunui & 17.97 & 0.55 & 0.71 & 0.51 \\
\hline Waingawa Masterton & 12.56 & -0.05 & 0.29 & 0.16 \\
\hline Wanaka & 6.07 & 0.86 & 0.83 & 0.33 \\
\hline Wanganui & 9.17 & -0.05 & 0.38 & 0.33 \\
\hline Westport Airport & 14.80 & 0.48 & 0.57 & 0.21 \\
\hline Whakatane & 20.11 & 0.10 & -0.28 & -0.41 \\
\hline
\end{tabular}

propagating slowly eastward past New Zealand. While the slow eastward propagation of the ACW around the Southern Ocean is influenced by tropical ENSO in the central and eastern South Pacific Ocean (Peterson and White 1998), in the vicinity of New Zealand the ACW is conditioned by coupled ocean-atmosphere interactions operating in the Indian and western Pacific sectors of the Southern Ocean.

In the present study, we have developed a statistical climate prediction system for forecasting autumn-winter temperature and precipitation over New Zealand based upon the regular slow eastward propagation of the ACW that occurred over the 14-yr record from 1982 to 1995. This system is based upon a two-tiered approach: in the first tier, the regular eastward propagation of the ACW in the Southern Ocean allows SST indices in the vicinity of New Zealand to be hindcast at lead times of $1 \mathrm{yr}$ with much better skill than can be achieved through persistence alone; in the second tier, statistical inferences are established between SST indices and New Zealand autumn-winter temperature and precipitation indices, allowing for the reconstruction of hindcasted time sequences of autumn-winter temperature and precipitation anomalies at individual station locations. With such short records, we were not able to conduct forecasting experiments; so only hindcasting experiments were conducted and these with limited numbers of temporal degrees of freedom. Even so, the regular wavelike character of the ACW and its statistical association with New Zealand autumn-winter temperature and precipitation anomalies allow us to predict the latter $1 \mathrm{yr}$ into the future (see Table 1) with significant skill at the $90 \%$ confidence level (i.e., 0.53 for 10 temporal degrees of freedom) for about half of the New Zealand stations. Whether this will translate into forecasting skill will depend upon the relative stationarity of the phase and amplitude of the ACW over the next decade or so.

Autumn-winter variability was chosen as the focus for this study because covarying SST and MSW anomalies associated with the ACW during these seasons are hypothesized to have a thermodynamical influence upon New Zealand temperature and precipitation (White et al. 1998). In the present study, we find autumn-winter temperature anomalies over New Zealand in an apparent thermal equilibrium with adjacent SST anomalies, that is, heated (cooled) by the warm (cool) SST anomalies, consistent with the model ACW simulated by White et al. (1998) in a coupled ocean-atmosphere numerical model. This physical interpretation differs from that of Basher and Thompson (1996), wherein New Zealand temperature and adjacent SST anomalies together are presumed heated by anomalous meridional heat advection in the lower troposphere, the latter understood to derive from meridional atmospheric teleconnections occurring in response to equatorial SST anomalies associated with ENSO. Furthermore, we find evidence that autumn-winter precipitation anomalies over New Zealand occur in response to three different precipitation 
mechanisms resulting from the interaction of the ACW and New Zealand, that is, anomalous cyclonicity over New Zealand, anomalous low-level moisture flux convergence over New Zealand, and anomalous orographic influences from westerly wind anomalies incident upon mountain ranges in South Island. These hypothesized physical mechanisms for how the ACW influences autumn-winter temperature and precipitation anomalies over New Zealand require additional confirmation; yet, at the same time, they offer an opportunity for progressing beyond the statistical climate prediction system presented here, replacing it with a dynamical climate prediction system based upon an ocean-atmosphere coupled model of the Southern Hemisphere. Numerical experiments with this coupled model would be expected to simulate not only the slow eastward propagation of covarying SST and MSW associated with the ACW, as White et al. (1998) have done, but also the associated temperature and precipitation anomalies over New Zealand as intrinsic aspects of interannual climate variability in the coupled ocean-atmosphere system of the Southern Hemisphere.

The reason that New Zealand autumn-winter precipitation indices' hindcast at 1-yr lead is better than the New Zealand autumn-winter temperature index is because the statistical climate prediction system used to hindcast temperature loses stationarity after 1992, while that for precipitation does not. This may be related to the broader band of period scales for the New Zealand temperature index (i.e., 4-6 yr) as compared with that for New Zealand precipitation indices (i.e., 3-4 yr), the latter yielding more stationary time sequences. Furthermore, the distribution of correlation between the New Zealand temperature index and regional SST anomalies finds it related to SST anomalies directly over and east of New Zealand. In the statistical climate prediction system we have developed here for both New Zealand temperature and precipitation, these high correlations with SST anomalies east and north of New Zealand have been ignored, with the focus instead on the SST anomalies directly over, south, and west of New Zealand where SST anomalies are more directly influenced by the slow eastward propagation of the ACW. As Peterson and White (1998) have demonstrated, interannual SST anomalies east and north of New Zealand are influenced by tropical ENSO. This suggests that further skill in the prediction of both New Zealand autumn-winter temperature and precipitation anomalies may accrue from consideration of the influences that tropical ENSO has on SST anomalies north and east of New Zealand.

Finally, Barnett et al. (1994) have described a twotiered dynamical climate prediction system for forecasting interannual climate change around the globe. This is based upon the dynamical prediction of eastern equatorial Pacific SST anomalies associated with ENSO using a coupled ocean-atmospheric model of the Pacific basin; this is followed by the subsequent nowcast of anomalous atmospheric circulation over the globe using a global atmospheric model, the latter simulating extratropical climate change through meridional atmospheric teleconnections driven by equatorial SST anomalies. Yet in the present study we have demonstrated an ability to predict autumn-winter temperature and precipitation over New Zealand without consideration for tropical ENSO, instead focusing upon the slow eastward propagation of the ACW around the Southern Ocean. In fact, previous efforts to associate New Zealand precipitation and stream flow anomalies to tropical ENSO have met with disappointment (Kidson and Gordon 1996; Moss et al. 1994). Meanwhile, White et al. (1998) have demonstrated that interannual atmospheric circulation anomalies throughout the Southern Ocean depend upon covarying SST and MSW anomalies associated with the ACW. This suggests that the prediction of autumn-winter temperature and precipitation anomalies over Argentina, Australia, Chile, Paraguay, South Africa, Tasmania, and Uruguay may similarly depend upon predicting the phase and amplitude of the ACW, more so than on predicting the phase and amplitude of tropical ENSO in the equatorial Pacific.

Acknowledgments. This research was supported by the Office of Global Programs of NOAA (NOAA NA 37GP0372) in concert with the Experimental Climate Prediction Center at Scripps and by the National Science Foundation, Division of Ocean Sciences (OCE9401514). Warren White is also supported by the National Aeronautics and Space Administration (NASA) under Contract NA27GPO-539. Our thanks extend to Ted Walker, who conducted the statistical analyses presented in this study, and to Andrea Fincham, who helped construct the figures. We also wish to thank Andrew Sturman at the University of Canterbury in Christchurch and Stephen Thompson at the New Zealand National Institute of Water and Atmospheric Research (NIWA) in Wellington for their insight into processes responsible for New Zealand precipitation.

\section{REFERENCES}

Barnett, T. P., and Coauthors, 1994: Forecasting global ENSO-related climate anomalies. Tellus, 46A, 381-397.

Basher, R., and C. S. Thompson, 1996: Relationship of air temperature in New Zealand to regional anomalies in sea surface temperature and atmospheric circulation. Int. J. Climatol., 16, 405-425.

Frankignoul, C., and R. W. Reynolds, 1983: Testing a dynamical model for middle latitude sea surface temperature anomalies. $J$. Phys. Oceanogr., 13, 1131-1145.

Gordon, N. D., 1986: The Southern Oscillation and New Zealand weather. Mon. Wea. Rev., 114, 371-387.

Graham, N. E., J. Michaelson, and T. P. Barnett, 1987: An investigation of the El Niño-Southern Oscillation cycle with statistical models. I, Predictor field characteristics. J. Geophys. Res., 92, 14 251-14 270.

Haney, R. L., 1986: Some SST anomalies I have known; thanks to J. Namias. Namias Symposium, J. Roads, Ed., SIO Reference Series, Vol. 86-17, 148-159.

Hoskins, B. J., and D. Karoly, 1981: The steady linear response of 
a spherical atmosphere to thermal and orographic forcing. $J$. Atmos. Sci., 38, 1179-1196.

Kalnay, E., and Coauthors, 1996: The NCEP/NCAR 40-Year Reanalysis Project. Bull. Amer. Meteor. Soc., 77, 437-471.

Kaylor, R. E., 1977: Filtering and decimation of digital time series. Institute of Physical Science and Technology Tech. Rep. BN 850, University of Maryland, College Park, MD, 14 pp.

Kidson, J. W., and N. D. Gordon, 1986: Interannual variations in New Zealand temperature and precipitation patterns. N.Z. J. Geol. Geophys., 29, 363-375.

Kraus, E. B., and R. E. Morrision, 1966: Local interactions between the sea and the air at monthly and annual time scales. Quart. J. Roy. Meteor. Soc., 92, 114-127.

Moss, M. E., C. P. Pearson, and A. I. McKerchar, 1994: The Southern Oscillation index as a predictor of the probability of low streamflows in New Zealand. Water Resour. Res., 30, 2717-2723.

Namias, J., 1972: Experiments in objectively predicting some atmospheric and oceanic variables for the winter of 1971-72. J. Appl. Meteor., 11, 1164-1174.

- 1985: Remarks on the potential for long-range forecasting. Bull. Amer. Meteor. Soc., 66, 165-173.

Palmer, T. N., and Z. Sun, 1985: A modeling and observational study of the relationship between sea surface temperature in the northwest Atlantic and the atmospheric general circulation. Quart. J. Roy. Meteor. Soc., 111, 947-975.

Peterson, R., and W. B. White, 1998: Slow oceanic teleconnections linking the Antarctic Circumpolar Wave with the tropical El Niño-South Oscillation. J. Geophys. Res., 103, 24 573-24 583.
Preisendorfer, R. W., and C. D. Mobley, 1988: Principal Component Analysis in Meteorology and Oceanography. Elsevier, 425 pp.

Qiu, B., and F.-F. Jin, 1997: Antarctic circumpolar wave: An indication of ocean-atmosphere coupling in the extratropics. Geophys. Res. Lett., 24, 2585-2588.

Reynolds, R. W., and D. C. Marsico, 1993: An improved real-time global sea surface temperature analysis. J. Climate, 6, 114-119.

Salinger, M. J., 1980a: New Zealand climate: I. Precipitation patterns. Mon. Wea. Rev., 108, 1892-1904.

_ 1980b: New Zealand climate: II. Temperature patterns. Mon. Wea. Rev., 108, 1905-1912.

Smagorinsky, J., 1953: The dynamical influence of large-scale heat sources and sinks on the quasi-stationary mean motions in the atmosphere. Quart. J. Roy. Meteor. Soc., 79, 342-366.

Snedecor, G. W., and W. G. Cochran, 1980: Statistical Methods. Iowa State University Press, $507 \mathrm{pp}$.

Sturman, A., and N. Tapper, 1996: The Weather and Climate of Australia and New Zealand. Oxford University Press, 476 pp.

Wallace, J. M., and Q.-R. Jiang, 1987: On the observed structure of the interannual variability of the observed ocean/atmosphere climate system. Atmospheric and Oceanic Variability, H. Cattle, Ed., Royal Meteorological Society, 17-43.

White, W. B., and R. Peterson, 1996: An Antarctic circumpolar wave in surface pressure, wind, temperature, and sea ice extent. $\mathrm{Na}$ ture, 380, 699-702.

, S.-C. Chen, and R. Peterson, 1998: The Antarctic Circumpolar Wave: A beta-effect in ocean-atmosphere coupling over the southern Ocean. J. Phys. Oceanogr., 28, 2345-2361. 